\title{
Restitution and genetic differentiation of salmon populations in the southern Baltic genotyped with the Atlantic salmon 7K SNP array
}

\author{
Anita Poćwierz-Kotus ${ }^{1}$, Rafał Bernaśs ${ }^{2}$, Matthew P Kent ${ }^{3}$, Sigbjørn Lien ${ }^{3}$, Egidijus Leliüna ${ }^{4}$, Piotr Dębowski ${ }^{2}$ \\ and Roman Wenne ${ }^{1 *}$
}

\begin{abstract}
Background: Native populations of Atlantic salmon in Poland, from the southern Baltic region, became extinct in the 1980s. Attempts to restitute salmon populations in Poland have been based on a Latvian salmon population from the Daugava river. Releases of hatchery reared smolts started in 1986, but to date, only one population with confirmed natural reproduction has been observed in the Slupia river. Our aim was to investigate the genetic differentiation of salmon populations in the southern Baltic using a 7K SNP (single nucleotide polymorphism) array in order to assess the impact of salmon restitution in Poland.
\end{abstract}

Methods: One hundred and forty salmon samples were collected from: the Polish Slupia river including wild salmon and individuals from two hatcheries, the Swedish Morrum river and the Lithuanian Neman river. All samples were genotyped using an Atlantic salmon 7K SNP array. A set of 3218 diagnostic SNPs was used for genetic analyses.

Results: Genetic structure analyses indicated that the individuals from the investigated populations were clustered into three groups i.e. one clade that included individuals from both hatcheries and the wild population from the Polish Slupia river, which was clearly separated from the other clades. An assignment test showed that there were no stray fish from the Morrum or Neman rivers in the sample analyzed from the Slupia river. Global FST Over polymorphic loci was high (0.177). A strong genetic differentiation was observed between the Lithuanian and Swedish populations $\left(F_{S T}=0.28\right)$.

Conclusions: Wild juvenile salmon specimens that were sampled from the Slupia river were the progeny of fish released from hatcheries and, most likely, were not progeny of stray fish from Sweden or Lithuania. Strong genetic differences were observed between the salmon populations from the three studied locations. Our recommendation is that future stocking activities that aim at restituting salmon populations in Poland include stocking material from the Lithuanian Neman river because of its closer geographic proximity.

\section{Background}

Atlantic salmon (Salmo salar, L) has considerable economic, social and environmental importance since it contributes to global and local economies through aquaculture, wild stock fisheries and recreational sport [1]. However, anthropogenic pressure and environmental factors have reduced natural populations of salmon, and thus, fisheries management has developed strategies for fish stocking in Pacific and Atlantic regions [2-5].

\footnotetext{
* Correspondence: RWenne@iopan.gda.pl

'Institute of Oceanology, Polish Academy of Sciences, Sopot 81-712, Poland Full list of author information is available at the end of the article
}

A range of potential ecological and genetic problems are associated with the release of artificially produced fish into wild populations [6,7]. Genetic and phenotypic differences may exist between hatchery fish and wild fish, which may affect how stocked and wild fish interact. Hatchery fish experience altered selection pressures i.e. high juvenile density and abundance of food may select for behavioral and physiological traits that are disadvantageous in natural conditions [6]. Thus, multigeneration hatchery stocks are likely to differ more from wild fish than first-generation stocks for which most of the changes are probably due to environmental effects. The use of non-native fish for stocking can cause the introduction of novel genetically-based features into the 
wild population and can break up co-adapted gene complexes that may lead to out-breeding depression [8].

The Baltic salmon is geographically and genetically distinct from other lineages of Atlantic salmon $[9,10]$. Most of the original genetic diversity of the wild Baltic salmon has been lost. Only 25 of the 90 original stocks have survived [11]. Juvenile salmon migrate out to the Baltic Sea to feed and grow and then migrate back to rivers to reproduce. Natal-river homing facilitates local adaptation because salmon return to environments with favorable spawning conditions [12]. The main reasons for the decline of wild stocks are hydroelectric constructions and over-exploitation of fish stocks in the Baltic Sea area [13].

To compensate for the decline of salmon populations, approximately 50 million salmon juveniles originating from hatcheries have been released by the Baltic countries, mainly Sweden and Finland, over the last ten years [14]. A survey of the genetic differentiation of contemporary Baltic salmon populations, as part of the North Atlantic range, has been undertaken using a range of genetic markers $[10,15]$. However, salmon from the southern Baltic are under-represented in these studies [16].

In Poland, the native Atlantic salmon has disappeared from all rivers i.e. first from the upper Vistula river in the 1950s, then from Pomeranian rivers in the 1960s, and finally the Drava river (Odra basin) by the end of the 1980s [17]. Year 1968 was most crucial since the Włocławek Dam power plant started operating on the Vistula river. Because of the complete extinction of salmon in Poland, a restitution program was initiated based on the Latvian population from the Daugava river [18]; it was not possible to use stocking material from the geographically closer Lithuanian Neman river at that time because of its small population size. Genetic studies based on allozymes [19] and microsatellites [16,20] revealed that the Latvian salmon population belonged to the Eastern group of Baltic salmon stocks. The first stocking of Polish rivers began in 1986 when 840 salmon smolts $(1+)$ were released. The restitution program has continued to this day and can be considered as only moderately successful. Effective natural spawning has been evidenced by the presence of a limited number of wild parr found only in the Slupia river [21,22]. In addition to released fish, fish straying from other rivers or their descendants may have contributed to the restituted population. Our aim was to investigate the genetic differentiation of salmon populations in the southern Baltic using a 7K SNP (single nucleotide polymorphism) array in order to assess the impact of salmon restitution in Poland. Salmon that were introduced and naturalized in the Slupia river were compared with their source stocks at Polish hatcheries and subsequently with two neighboring populations from Sweden and Lithuania.

\section{Methods}

\section{Sampling, DNA isolation and SNP (single nucleotide polymorphism) genotyping}

Salmon samples from 28 individuals at each location were collected in 2011 from five locations in the southern Baltic: in Poland, wild parr from the Slupia river (PS) and parr from the two hatcheries Gabriel-Żelkówko (PHG) and Aquamar-Miastko (PHA); in Sweden, wild smolts from the Morrum river (SM); and in Lithuania, wild adults from the Neris (LN) river that is a tributary of the Neman river (Figure 1). Wild juvenile salmon from natural reproduction were electrofished in the Slupia river. DNA was extracted from fin clip samples with the Qiagen DNeasy 96 Blood \& Tissue kit according to the manufacturer's recommendations. DNA quality was analyzed on $1.0 \%$ agarose gels. DNA was quantified with a NanoDrop device and diluted to final concentrations of 50 to $100 \mathrm{ng} / \mu \mathrm{L}$. DNA genotyping was performed using the Atlantic salmon Illumina 7K SNP chip [10] at the Centre for Integrative Genetics (CIGENE) in Norway.

\section{Validation of SNPs}

Of the 5568 genotyped SNPs, 1640 were rejected as they failed in one or more of the following criteria: multi-site SNPs, paralogous SNPs, monomorphic SNPs and SNPs with null alleles. Mitochondrial SNPs were also excluded from the analysis. An accepted threshold of missing data rate was established at $80 \%$, which excluded 13 SNPs. In total, 488 SNPs were found monomorphic for all the analysed populations and were excluded from further analysis. Analysis of SNP allele frequency revealed that 209 SNPs had a MAF (minor allele frequency) less than 0.01 and they were removed. Finally, 3218 polymorphic SNPs remained for the analyses.

\section{Analysis of SNP polymorphism, genetic structure and phylogenetic relationships}

The number of polymorphic SNPs and their observed and expected heterozygosity ( $\mathrm{Ho}$ and $\mathrm{He}$ ) were calculated using the Arlequin 3.5.1.2 software [23] with the Markov chain exact probability test with a chain length of 1000000 and 100000 dememorization steps. To adjust the $\mathrm{P}$ value for each pair in multiple testing, Bonferroni corrections were applied. For each population, allele frequencies were calculated using the Arlequin 3.5.1.2 software and MAF were estimated using Excel spreadsheet formulas. We also used the Arlequin software to perform an analysis of molecular variance (AMOVA) with 10000 permutations to estimate variance components between Atlantic salmon populations and between individuals within populations by applying the bootstrapped $\mathrm{F}_{\mathrm{ST}}$ estimator of Weir and Cockerham [24]. To estimate within-population diversity, the average number 


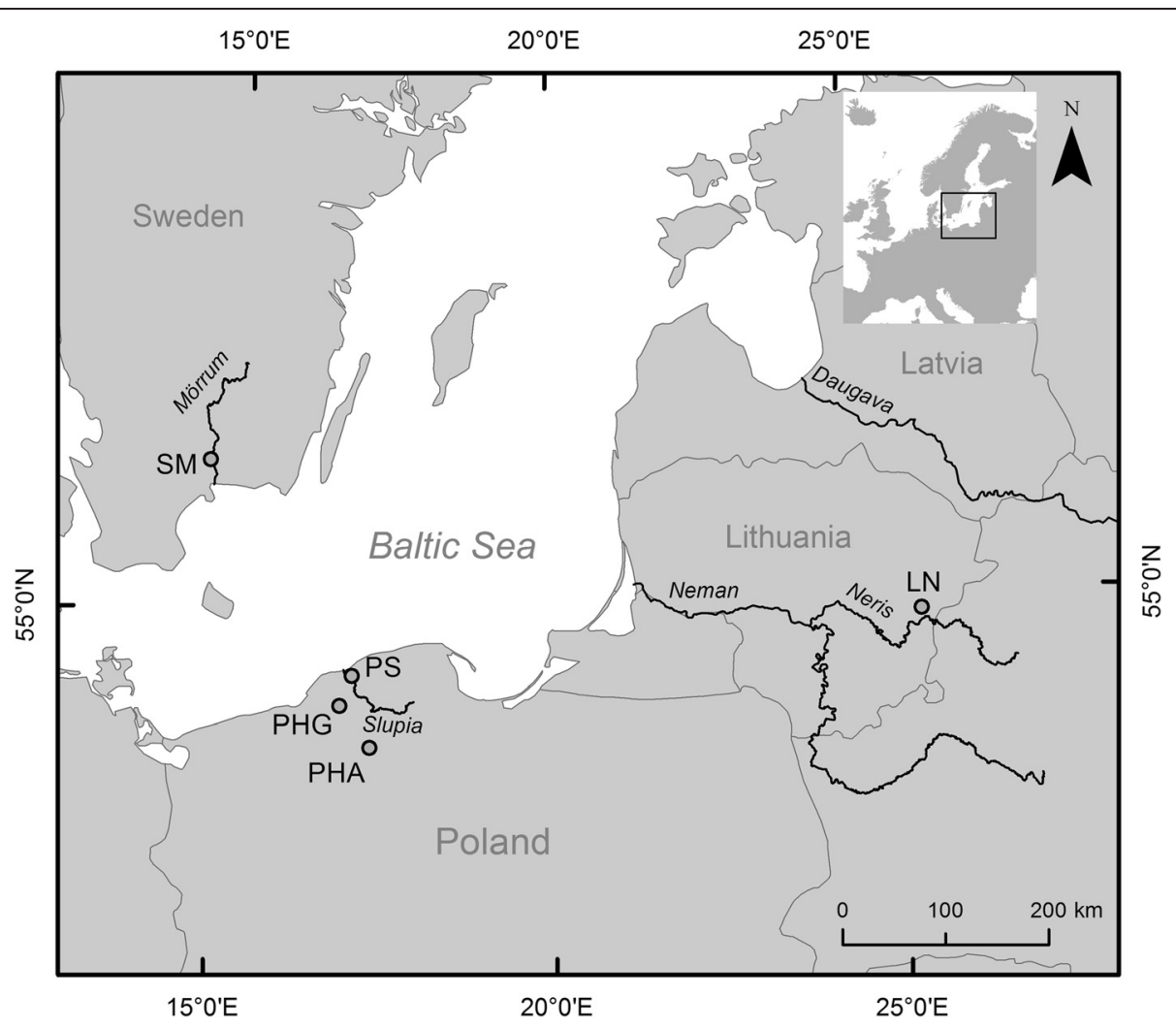

Figure 1 Map of salmon sample sites in the Southern Baltic. PS = Poland, Slupia river; PHA = Poland, hatchery Aquamar; PHG = Poland, hatchery Gabriel; SM = Sweden, Morrum river; LN = Lithuania Neman river.

of pairwise differences was calculated using Arlequin. Pairwise $\mathrm{F}_{\mathrm{ST}}$ was estimated in two datasets both for all SNPs and only outlier SNPs. The first dataset comprised the full geographic distribution i.e. the Latvian-Polish PL pooled population (i.e. pooled PS, PHA and PHG populations), the Lithuanian LN and Swedish SM populations, and the second dataset contained only the Polish PS, PHA and PHG populations.

Clustering of salmon populations was examined using Structure 2.0 software [25] assuming K equal to 1 to 8 . Choosing a $\mathrm{K}$ value greater than 5 (the number of populations) was justified by the probability of identifying sub-populations among the studied populations. The Structure algorithm included the admixture model and correlated allele frequencies. Five iterations of each $\mathrm{K}$ value were conducted with 200000 Markov chain Monte-Carlo (MCMC) iterations and 100000 burn-in iterations. CLUMPP v. 1.1.1 [26] was applied to avoid the potential effect of generating several distinct solutions for the estimated cluster membership coefficients in spite of identical initial conditions The average cluster membership was calculated using the LargeK Greedy algorithm.

Distruct v. 1.1 [27] was used to visualize the results from the CLUMPP analysis by generating bar plots that depict the clustering results with the highest probability under the model. Plots show population and individual levels of stratification.

Table 1 Levels of genetic diversity for five salmon populations from the southern Baltic Sea

\begin{tabular}{|c|c|c|c|c|c|c|c|c|}
\hline Population & $\mathrm{Nb}$ individuals & $\mathrm{Nb}$ polymorphic loci & Mean nb alleles & Ho & $\mathrm{He}$ & $\begin{array}{l}\text { Nb loci deviating } \\
\text { from HWE* }\end{array}$ & $\begin{array}{l}\text { After Bonferroni } \\
\text { correction }\end{array}$ & $F_{\text {is }}$ \\
\hline PHA & 28 & 2654 & 1.825 & 0.330 & 0.327 & 23 & 5 & -0.00517 \\
\hline PHG & 28 & 2620 & 1.814 & 0.339 & 0.331 & 68 & 2 & -0.02221 \\
\hline LN & 28 & 2461 & 1.765 & 0.339 & 0.323 & 83 & 6 & -0.04648 \\
\hline SM & 28 & 3030 & 1.942 & 0.325 & 0.325 & 85 & 2 & -0.00038 \\
\hline PS & 28 & 2645 & 1.822 & 0.337 & 0.327 & 88 & 6 & -0.02486 \\
\hline
\end{tabular}

PHA = Polish Hatchery Aquamar-Miastko population; PHG = Polish Hatchery Gabriel-Żelkówko population; LN = Lithuanian Neman river population; SM = Swedish Morrum river population; $\mathrm{PS}=$ Polish Slupia river population; ${ }^{*} \mathrm{P}<0.05$. Bonferroni correction was applied. 
Table 2 Analysis of molecular variance (AMOVA) applying the $F_{S T}$ estimator of Weir and Cockerham [24] calculated for three models

\begin{tabular}{|c|c|c|c|c|}
\hline & \multicolumn{2}{|l|}{ Between populations } & \multicolumn{2}{|c|}{ Between individuals within populations } \\
\hline & Variance component & $\%$ variation & Variance component & $\%$ variation \\
\hline Countries & 129.15 & 22.65 & 441.14 & 77.35 \\
\hline Wild populations & 141.05 & 24.25 & 440.65 & 75.75 \\
\hline Polish populations & 7.46 & 1.69 & 433.68 & 98.31 \\
\hline
\end{tabular}

Countries = PL (pooled Polish-Latvian populations), LN (Lithuanian Neman river) and SM (Swedish Morrum river) populations; Wild populations = PS (Polish Slupia river), LN and SM populations; Polish populations = PHA (Polish Hatchery Aquamar-Miastko), PHG (Polish Hatchery Gabriel-Żelkówko) and PS populations.

Structure Harvester [28] was used to determine the appropriate K value following Evanno et al. [29]. Principal Coordinates Analysis (PCoA) was performed in GenAlex [30,31] to visualize the relationships between populations. Phylogenetic relationships between the salmon populations were constructed using the POPULATIONS software version.1.2.32 [32] with the Neighbour-Joining (NJ) method and Nei's standard genetic distance Ds [33]. Bootstrapping was carried out with 5000 replicates over loci, using the grouped population option.

To determine the most likely origin of all 140 salmon individuals, assignment tests were conducted using GeneClass2 [34] with the allele frequency-based method [35]. This allowed us to identify potential migrants or their descendants.

\section{Detection of outlier SNPs}

The hierarchical island model with 100000 simulations implemented in Arlequin was used to detect outlier SNPs. SNPs that had $\mathrm{F}_{\mathrm{ST}}$ values for a given value of heterozygozity higher than expected on the basis of neutral variation were considered. SNPs that had $\mathrm{F}_{\mathrm{ST}}$ values that were outside the $99 \%$ quantile based on coalescent simulations were considered as candidates for diversifying selection [36]. Significance of $\mathrm{F}_{\mathrm{ST}}$ distributions for regular and outlier SNPs was tested using the Bayesian estimation software (BEST) [37] that supersedes the $t$ test [37].

\section{Results}

Analysis of the genetic polymorphism and diversity of Salmo salar populations

The five salmon samples used in this work represent wild and hatchery populations. One hundred and forty individuals were genotyped using 5568 SNPs, of which 3218 were diagnostic markers. The number of polymorphic SNPs for each population varied and ranged from 2461 for the LN population to 3030 for the SM population. For the PS wild population and the PHA and PHG populations, the numbers of polymorphic SNPs were similar i.e. 2645, 2654 and 2620, respectively (Table 1). Mean numbers of SNP alleles were also congruent for the PS, PHA and PHG populations and the lowest and highest values were observed for LN (1.765) and SM (1.942) populations, respectively.
Observed heterozygosities were similar for all populations and ranged from 0.325 for SM to 0.339 for PHG and $\mathrm{LN}$ populations and expected heterozygosities ranged from 0.323 for LN to 0.331 for PHG populations. In all cases, differences between $H o$ and $H e$ were relatively small, with the largest difference observed for the LN (0.016) population while for SM, it was null. Before Bonferroni correction, deviations from Hardy-Weinberg expectations ranged from 23 for the PHG to 88 for the PS populations (Table 1). After Bonferroni correction, only a few SNPs remained significant from two for PHG and SM to six for LN and PS populations. Overall, $F_{I S}$ reached a value of -0.022 and was non-significant $(P<0.05)$.The average population specific $\mathrm{F}_{\mathrm{IS}}$ estimated for each population was also non-significant $(\mathrm{P}<0.05)$ (Table 1$)$.

AMOVA was conducted for three scenarios: "Countries", "Wild populations", and "Polish populations" (Table 2). The largest amount of variance was found among individuals within each population. For the "Countries" scenario, overall genetic differentiation $\left(\mathrm{F}_{\mathrm{ST}}\right)$ was equal to 0.226 which indicates a high level of differentiation. For comparison, a test was performed for a scenario that comprised only the wild populations and overall $\mathrm{F}_{\mathrm{ST}}$ was even higher and reached 0.242 . Overall $\mathrm{F}_{\mathrm{ST}}$ was lowest (0.016) for the scenario that comprised only the Polish populations.

All pairwise comparisons of genetic differentiation between populations were significant $(\mathrm{P}<0.05)$ (Tables 3 and 4). Pairwise $\mathrm{F}_{\mathrm{ST}}$ analysis of the various geographic locations showed that PL vs. SM (0.21) and SM vs. LN (0.27) were genetically differentiated, while PL vs. LN and PL vs. SM were not. When only the Polish populations were analyzed, PS vs. PHG and PS vs. PHA had

Table $3 \mathrm{~F}_{\mathrm{ST}}$ values for pairwise comparisons of salmon PL, LN and SM populations based on geographical location (below the diagonal) and average number of pairwise differences within populations (on the diagonal)

\begin{tabular}{llll}
\hline & PL & LN & SM \\
\hline PL & 876.431 & & \\
LN & 0.218 & 795.614 & \\
SM & 0.217 & 0.275 & 983.046 \\
\hline
\end{tabular}

$\mathrm{PL}=$ pooled Polish-Latvian; $\mathrm{LN}=$ Lithuanian Neman river; $\mathrm{SM}=$ Swedish Morrum river; all values were significant for a $P$ value of 0.05 . 
Table $4 \mathbf{F}_{\mathrm{ST}}$ values for pairwise comparisons of salmon PHA, PHG and PS Polish populations (below the diagonal) and average number of pairwise differences within populations (on the diagonal)

\begin{tabular}{llll}
\hline & PHA & PHG & PS \\
\hline PHA & 865.342 & & \\
PHG & 0.008 & 865.480 & \\
PS & 0.019 & 0.022 & 864.433 \\
\hline
\end{tabular}

PHA = Polish Hatchery Aquamar-Miastko; PHG = Polish Hatchery Gabriel-Żelkówko; $\mathrm{PS}=$ Polish Slupia river; all values were significant for a $\mathrm{P}$ value of 0.05 .

nearly equal $\mathrm{F}_{\mathrm{ST}}$ values at 0.02 . The $\mathrm{SM}$ population was the most genetically differentiated while the three polish PS, PHG and PHA populations had very similar, but lower, levels of within-population differentiation than SM. Finally, the population that was the least genetically differentiated was LN.

\section{Analysis of outliers}

One hundred and twenty six SNPs for which $\mathrm{F}_{\mathrm{ST}}$ values were outside the $99 \%$ quantile were identified as potential candidates for divergent selection (Figure 2). The global $F_{\mathrm{ST}}$ calculated for this set of 126 outlier loci for the pooled Polish populations was much higher i.e. 0.656 compared to that calculated for the 3218 polymorphic SNPs (0.226). Pairwise $\mathrm{F}_{\mathrm{ST}}$ values increased significantly for all comparisons between populations in both analyses except for PS vs. PHA and PS vs. PHG for which $\mathrm{F}_{\mathrm{ST}}$ values decreased non significantly $(\mathrm{P}=0.073)$ from 0.019 to 0.014 for PS vs. PHA and from 0.022 to 0.015 for PS vs. PHG (Tables 5 and 6).

\section{Analysis of population genetic structure and genetic relationships between populations}

Bayesian clustering methods were applied to examine genetic relationships between the five salmon populations and provided information about the assignment of particular individuals to groups based on their genetic similarity. The results obtained using the Evanno method [29] indicated that the mean log likelihood against $\mathrm{K}$ showed a plateau at $\mathrm{K}=3$ and the maximum value of $\Delta \mathrm{K}$ was for $\mathrm{K}=3(\Delta \mathrm{K}=8521)$ (Figure $3 \mathrm{C})$. At $\mathrm{K}=3$, the three Polish PS, PHA and PHG populations were separated from the Lithuanian LN and Swedish SM populations (Figure 3 ).

Results from the assignment test showed that $85.00 \%$ of all individuals were assigned to the population they were sampled from (Table 7). The frequency of selfassignment varied from $60.17 \%$ for PHG to $100 \%$ for LN and SM. The percentage of correctly assigned individuals from the PS population was $78.61 \%$ while $20.43 \%$ and $0.95 \%$ of the PS individuals were assigned to the breeding PHA and PHG populations, respectively. However, individuals from these hatchery stocks were more mixed with each other than with PS itself. The main reason for such high similarity is that salmon eggs from PHA have

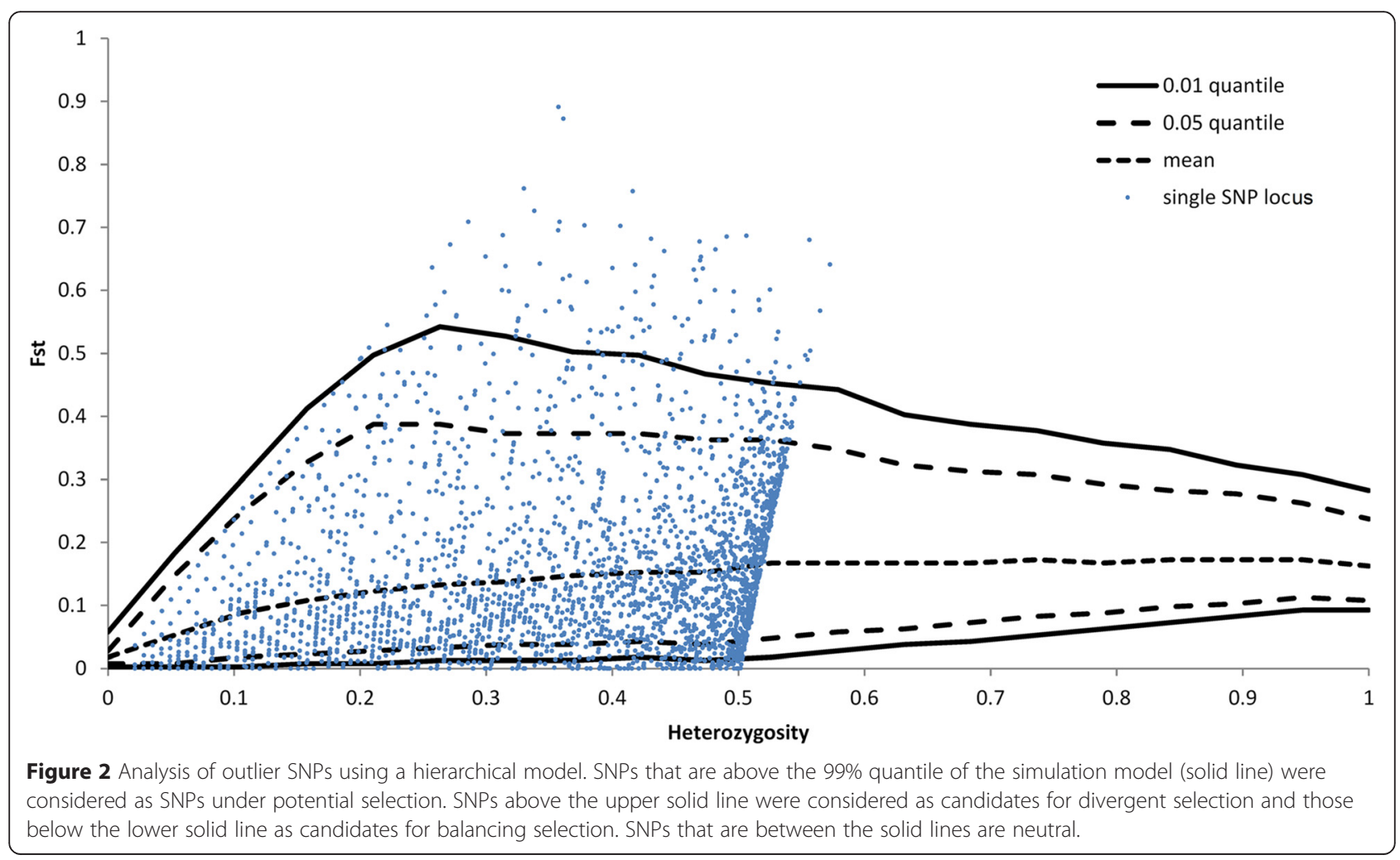


Table 5 Pairwise estimates of $\mathrm{F}_{\mathrm{ST}}$ calculated using the 126 outlier SNPs for salmon PL, LN and SM populations based on geographical location

\begin{tabular}{llll}
\hline & PL & LN & SM \\
\hline PL & - & & \\
$L N$ & 0.679 & - & \\
SM & 0.680 & 0.589 & - \\
\hline
\end{tabular}

$\mathrm{PL}=$ pooled Polish-Latvian; $\mathrm{LN}=$ Lithuanian Neman river; $\mathrm{SM}=$ Swedish Morrum river; all values were significant for a $P$ value of 0.05 .

been transferred to PHG at certain times over the last decade. $83.04 \%$ of the individuals from the PHA population were self-assigned while $16.98 \%$ were assigned to PHG, and $60.17 \%$ of the individuals from the PHG population were self-assigned while $39.82 \%$ were assigned to PHA. Assignment tests indicated that among all the individuals investigated from the Polish populations, no genotypes from the Swedish (Morrum) or Lithuanian (Neman) samples were observed.

Individual assignment results were consistent with the results of the pairwise $\mathrm{F}_{\mathrm{ST}}$ analysis: $\mathrm{LN}$ and $\mathrm{SM}$ populations showed the highest pairwise $\mathrm{F}_{\mathrm{ST}}$ values and had a self-assignment rate of $100 \%$. Similar relationships were observed with both PCoA and Structure analysis [See Additional file 1: Figure S1].

Genetic relationships between salmon populations based on Structure analysis were consistent with the results obtained from the phylogenetic analysis. A neighbour-joining (NJ) tree was constructed and the branches were supported by high bootstrap values (Figure 4). The NJ method showed that the genotypes investigated belonged to three major clusters: cluster (1) included all genotypes from the Lithuanian LN population, cluster (2) all genotypes from the Swedish SM population and cluster (3) all genotypes from the three Polish populations PS, PHA and PHG.

\section{Discussion}

In this study, a 7K SNP microarray was used to analyze the genetic relationships between hatchery and wild salmon populations from the southern Baltic. The Polish wild population from the Slupia river (PS) and the two hatchery Polish populations PHA and PHG formed one clade. However, the PS individuals that were caught were

Table 6 Pairwise estimates of $\mathrm{F}_{\mathrm{ST}}$ calculated using the 126 outlier SNPs for salmon PHA, PHG and PS Polish populations

\begin{tabular}{llll}
\hline & PHA & PHG & PS \\
\hline PHA & - & & \\
PHG & 0.021 & - & - \\
PS & 0.014 & 0.015 & - \\
\hline
\end{tabular}

PHA = Polish Hatchery Aquamar-Miastko; PHG = Polish Hatchery Gabriel-Żelkówko; $\mathrm{PS}=$ Polish Slupia river; all values were significant for a $\mathrm{P}$ value of 0.05 .

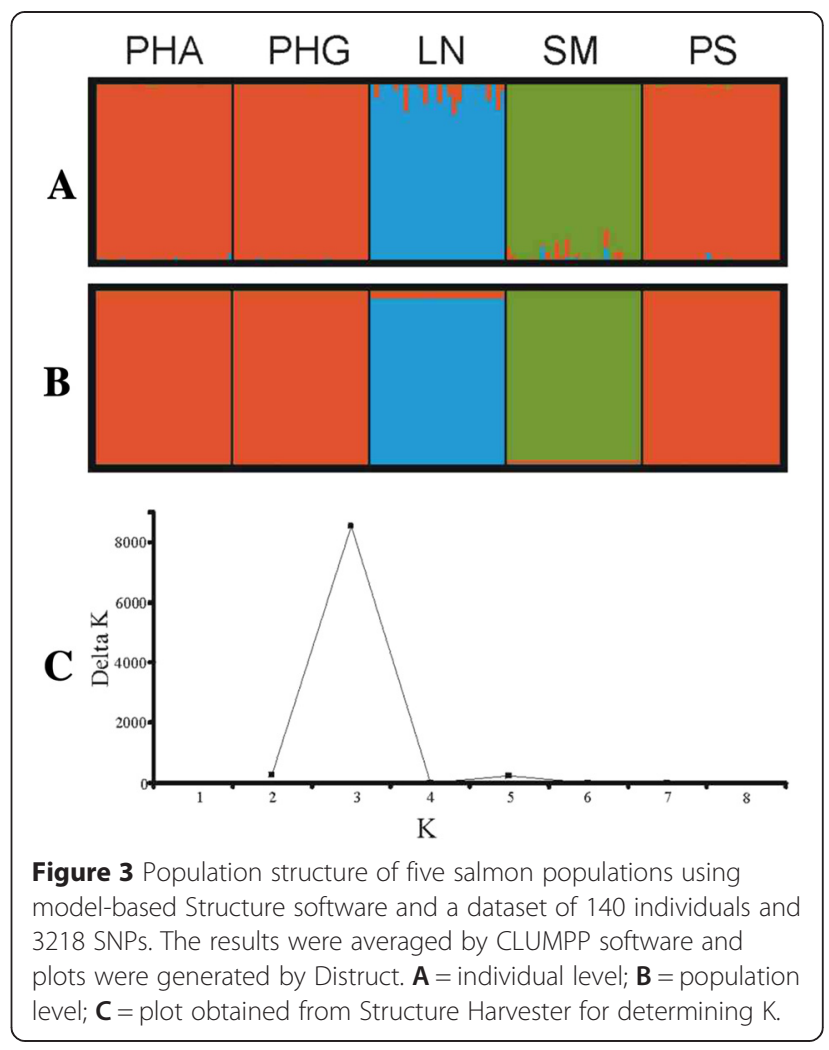

born in the Slupia river where is located a recovering and naturally reproducing salmon population. Bayesian analysis and assignment tests showed that wild specimens sampled from the Slupia river were not the progeny of fish straying from Sweden or Lithuania but were the progeny of fish released from the hatcheries that were established by using imported stocking material from the Daugava river. Salmon eggs have been imported several times i.e. in 1985, 1987 and each year between 1994 and 1999 [17]. Previously, Popović [18] had already reported the similarity between Polish hatchery populations, including PHA and PHG, and the population from the Daugava river.

$\mathrm{F}_{\text {IS }}$ estimates for all Polish populations revealed that the genetic diversity of the Polish salmon does not seem

Table 7 Results of the assignment tests computed using GeneClass2 software based on a frequency method [34]

\begin{tabular}{llllll}
\hline & PHA & PHG & LN & SM & PS \\
\hline PHA & $83.04 \%$ & $16.98 \%$ & $0 \%$ & $0 \%$ & $0 \%$ \\
PHG & $39.82 \%$ & $60.17 \%$ & $0 \%$ & $0 \%$ & $0 \%$ \\
LN & $0 \%$ & $0 \%$ & $100 \%$ & $0 \%$ & $0 \%$ \\
SM & $0 \%$ & $0 \%$ & $0 \%$ & $100 \%$ & $0 \%$ \\
PS & $20.43 \%$ & $0.95 \%$ & $0 \%$ & $0 \%$ & $78.61 \%$
\end{tabular}

Results are presented using the percent score of the most likely source population (threshold $\mathrm{P}<0.05$ ); $\mathrm{PHA}=$ Polish Hatchery Aquamar-Miastko; PHG = Polish Hatchery Gabriel-Żelkówko; LN = Lithuanian Neman river; $\mathrm{SM}=$ Swedish Morrum river; $\mathrm{PS}=$ Polish Slupia river . 


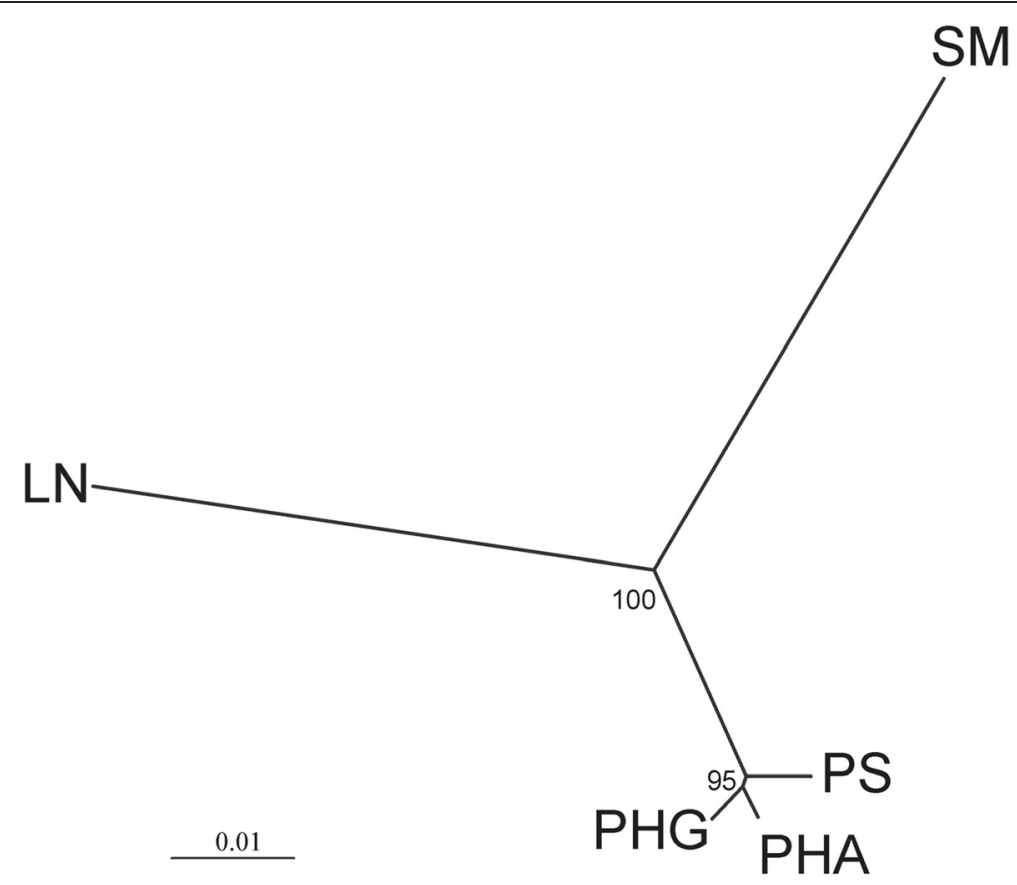

Figure 4 A neighbor-joining tree constructed using Nei's distances among the five salmon populations and generated by POPULATIONS V.1.2.32 [32] software. Bootstrap probabilities are shown on the tree.

to be affected by inbreeding. Therefore, the Polish hatchery Aquamar (PHA) stock consisting of a large number of specimens (about 700 females and 300 males) may be sufficient to preserve a hatchery strain against unfavorable factors such as inbreeding effects, genetic drift and loss of genetic diversity $[18,37,38]$. No inbreeding was observed for the other populations either. However, because sample size was small (28 specimens per hatchery) and SNPs were mainly biallelic, $\mathrm{F}_{\mathrm{IS}}$ values need to be interpreted with caution since negative selection processes or domestication occurring in hatchery stocks cannot be excluded. In spite of the observed small, but significant, differences between the wild PS population and PHA and PHG hatchery stocks, the wild population was closely related to the stocking material.

The three Polish populations, PS, PHA and PHG separated well from the Lithuanian LN and Swedish SM populations. The results obtained from the genetic structure analysis suggested that the most significant subdivision is the geographic subdivision. The Polish populations irrespective of the site of sampling had the same ancestral population, which was confirmed by the results of NJ reconstruction and PCoA.

The stocking material used in the two sampled hatcheries in Poland came from Latvia (Daugava river) as eyed eggs and were imported each year between 1994 and 1999. Initially, the stocking material was reared and released at the smolts stage and later, an own-hatchery stock, located in Aquamar, was created. Currently, all stocking material in the Slupia basin is based on releases of smolts that are marked by clipping the small adipose fin near the tail. According to the results of studies on scales and tagging experiments, the rate of potential straying of Baltic salmon is relatively low (on average $4 \%$ ) and the risk of contamination for neighboring native populations is near zero [39].

Based on microsatellite analyses [16], salmon from the Daugava river in Latvia represent eastern Baltic populations while the salmon sampled from the Morrum river in Sweden represent the southern Baltic group. Our results show that the population from the Neman river in Lithuania constitutes a third clade that is clearly separated from the other populations. This native population could be closely related to the extinct Polish salmon populations. It is recommended that future stocking activities that aim at restituting salmon populations in Poland, include material from the Neman river because of its closer geographic proximity.

However, in this study, the lowest genetic variability was observed for the LN population, which may be the result of a large reduction in effective population size in the past. Therefore, the genetic quality of this new potential stocking material from the Neman river needs to be analyzed to assess the genetic consequences on the recently established salmon population in the Słupia river in Poland prior to any releases. 
The LN population is characterized by the smallest number of polymorphic SNPs and smallest mean number of alleles. In contrast, among all analyzed populations, diversity measures were greatest for the SM population. The current annual wild production of smolts is about 50000 per year in the Neman and 60 000 in the Morrum rivers [39]. Both salmon populations from Morrum and Neman rivers have been classified as "wild" according to HELCOM (Baltic Marine Environment Protection Commission - Helsinki Commission) indicators. However, the Neman salmon is considered as more threatened because the size of its reproductive population is smaller. The Polish Slupia population has been described as "mixed" with studies reporting some annual wild rearing and continuous releases of reared fish [22,39]. Genetic differentiation between these populations could potentially have biological relevance by reflecting local adaptation or diversification of quantitative traits. Management based on the specificities of each river has been recommended by HELCOM [22] and by participants of The Baltic Salmon Symposium and Workshop held at the Stockholm University in February 9-10, 2012.

Previous research showed that Salmonidae, including sea trout (Salmo trutta m. trutta) and Atlantic salmon, underwent a bottleneck event [40,41]. The low level of diversity can be explained by this early bottleneck in the salmon populations of Lithuanian rivers. These populations originate from different evolutionary lineages related to the existence of distinct refugia. It has been suggested that the Baltic Sea was colonized from up to three distinct refugia: the Gulf of Bothnia from an Atlantic refugium, the Gulf of Finland from an eastern ice lake refugium and the southern Main Basin from a refugium that was presumably located in the basin of Neman, Vistula, Odra and Elbe rivers [16,42].

\section{Conclusions}

In this study, we exploited a high-throughput SNP microarray technology that provided extensive information on the polymorphism of nuclear DNA in populations of salmon in the Southern Baltic. Salmon stocking material imported to Poland from Latvia (Daugava river) differed from southern Sweden and Lithuanian populations. Wild smolts from the restituted population in the Slupia river originated from fish released from hatchery stocks. No stray fish or progeny of fish straying from Sweden or Lithuania were found in the restituted population of the Slupia river. Our recommendation is that future stocking activities that aim at restituting salmon populations in Poland, include stocking material from the Neman river because of its closer geographic proximity.

\section{Additional file}

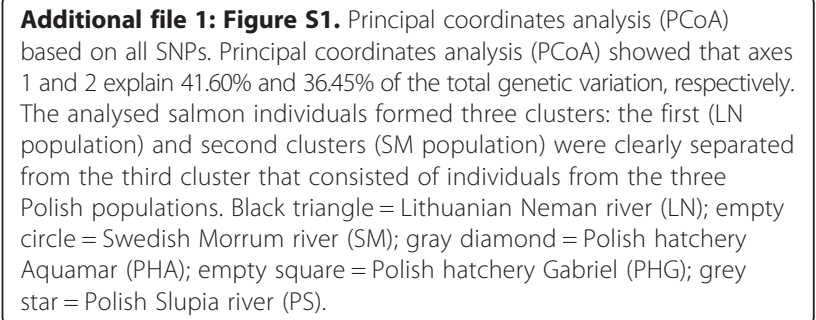

Competing interests

The authors declare that they have no competing interests.

\section{Authors' contributions}

$\mathrm{RB}$ and EL collected fish samples. APK and MPK conducted the molecular work. PD and SL participated in design of the study. RW conceived of the study, and participated in its design and coordination. APK and RB analysed the data. EL contributed information for writing the manuscript. APK, RB, PD and RW wrote the manuscript. All authors read and approved the final manuscript.

\section{Acknowledgements}

This study was partially funded by the Ministry of Agricultural and Rural Development Board, Poland, operating under the "Stocking of Polish Marine Areas" programme and by statutory topic S-25 in the IFI Olsztyn, and by project \#397/NcGRASP/2009/0 of the Ministry of Science and Higher Education in Poland to RW and statutory topic IV.1 in the IO PAS. The authors are grateful to the anonymous reviewers for their constructive comments on the manuscript prior to publication.

\section{Author details}

${ }^{1}$ Institute of Oceanology, Polish Academy of Sciences, Sopot 81-712, Poland. ${ }^{2}$ Department of Migratory Fishes in Gdansk 80-298, Inland Fisheries Institute, Olsztyn 10-719, Poland. ${ }^{3}$ Centre for Integrative Genetics (CIGENE), Norwegian University of Life Sciences, Ås 1432, Norway. ${ }^{4}$ Institute of Ecology of Nature Research Centre, Vilnius 08412, Lithuania.

Received: 9 July 2014 Accepted: 21 April 2015

Published online: 06 May 2015

\section{References}

1. Davidson WS, Koop BF, Jones SJM, Iturra P, Vidal R, Maass A, et al. Sequencing the genome of the Atlantic salmon (Salmo salar). Genome Biol. 2010;11:403.

2. Beechie T, Imaki H, Greene J, Wade A, Wu H, Pess G, et al. Restoring salmon habitat for a changing climate. River Res Appl. 2013;29:939-60.

3. Ritter JA. The contribution of Atlantic salmon (Salmo salar L.) enhancement to a sustainable resource. ICES J Mar Sci. 1997;54:1177-87.

4. Hilborn R, Eggers D. A review of the hatchery programs for pink salmon in Prince William Sound and Kodiak Island, Alaska. T Am Fish Soc. 2000;129:333-50.

5. Jokikokko E, Kallio-Nyberg I, Saloniemi I, Jutila E. The survival of semi-wild, wild and hatchery-reared Atlantic salmon smolts of the Simojoki river in the Baltic Sea. J Fish Biol. 2006;68:430-42.

6. Einum S, Fleming IA. Implications of stocking: ecological interactions between wild and released salmonids. Nord J Freshw Res. 2001;75:56-70.

7. Karlsson S, Moen T, Lien S, Glover KA, Hindar K. Generic genetic differences between farmed and wild Atlantic salmon identified from a 7K SNP-chip. Mol Ecol Resour. 2011;11:247-53.

8. Gharrett AJ, Smoker WW. Two generations of hybrids between even- and odd-year pink salmon (Oncorhynchus gorbuscha): a test for outbreeding depression? Can J Fish Aquat Sci. 1991;48:1744-9.

9. Rappe C, Ranke W, Soler T, Funegärd P, Karlsson L, Thorell L. Baltic salmon rivers - status in the late 1990s as reported by the countries in the Baltic Region. International Baltic Sea Fishery Commission (IBSFC). Baltic Marine Environment Commission - Helsinki Commission (HELCOM). The Swedish Environment Protection Agency. The Swedish National Board of Fisheries. 1999;69.

10. Bourret $V$, Kent MP, Primmer CR, Vasemägi A, Karlsson S, Hindar K, et al. SNP-array reveals genome wide patterns of geographical and potential 
adaptive divergence across the natural range of Atlantic salmon (Salmo salar). Mol Ecol. 2013;22:532-51.

11. Koljonen ML. Conservation goals and fisheries management units for Atlantic salmon in the Baltic Sea area. J Fish Biol. 2001;59:269-88.

12. McDowall RM. Anadromy and homing: two life-history traits with adaptive synergies in salmonid fishes? Fish Fish. 2001;2:78-85.

13. Koljonen ML. Annual changes in the proportions of wild and hatchery Atlantic salmon (Salmo salar) caught in the Baltic Sea. ICES J Mar Sci. 2006;63:1274-85

14. ICES. Report of the Baltic salmon and trout assessment working group (WGBAST): 3-12 April 2013. 08th ed. Tallinn: ICES CM 2013/ACOM; 2013. p. 334.

15. Ryynänen $H J$, Tonteri A, Vasemägi A, Primmer CR. A comparison of biallelic markers and microsatellites for the estimation of population and conservation genetic parameters in Atlantic salmon (Salmo salar). J Hered. 2007:98:692-704

16. Säisä M, Koljonen ML, Gross R, Nilsson J, Tähtinen J, Koskiniemi J, et al. Population genetic structure and postglacial colonization of Atlantic salmon (Salmo salar) in the Baltic Sea area based on microsatellite DNA variation. Can J Fish Aquat Sci. 2005;61:1887-904.

17. Bartel R. The restoration of Atlantic salmon (Salmo salar L.) in Poland. Arch Pol Fish. 2001:9:219-28.

18. Popović D. Genetic polymorphism of populations of four anadromous fish species restituted in Polish waters. PhD thesis. Warsaw University, Institute of Genetics and Biotechnology, Faculty of Biology. 2008;138.

19. Koljonen ML, Jansson H, Paaver T, Vasin O, Koskiniemi J. Phylogeographic lineages and differentiation pattern of Atlantic salmon (Salmo salar) in the Baltic Sea with management implications. Can J Fish Aquat Sci. 1999;56:1766-80.

20. Koljonen ML, Pella JJ, Masuda M. Classical individual assignments versus mixture modeling to estimate stock proportions in Atlantic salmon (Salmo salar) catches from DNA microsatellite data. Can J Fish Aquat Sci. 2005;62:2143-58

21. Bernaś R, Dębowski P, Bartel R, Radtke G, Miller M, Skóra M. Occurrence of juvenile salmon, Salmo salar L., from natural spawning in the Slupia River (northern Poland). Arch Pol Fish. 2009;17:317-21.

22. Baltic Marine Environment Protection Commission. HELCOM assessment of salmon (Salmo salar) and sea trout (Salmo trutta) populations and habitats in rivers flowing to the Baltic Sea. Balt Sea Environ Proc. 2011;126A:1-77.

23. Excoffier L, Lischer HEL. Arlequin suite ver 3.5: a new series of programs to perform population genetics analyses under Linux and Windows. Mol Ecol Resour. 2010;10:564-7.

24. Weir BS, Cockerham CC. Estimating F-statistics for the analysis of population structure. Evolution. 1984:38:1358-70.

25. Pritchard JK, Stephens M, Donnelly P. Inference of population structure using multilocus genotype data. Genetics. 2000;155:945-59.

26. Jakobsson M, Rosenberg NA. CLUMPP: a cluster matching and permutation program for dealing with label switching and multimodality in analysis of population structure. Bioinformatics. 2007;23:1801-6.

27. Rosenberg NA. DISTRUCT: a program for the graphical display of population structure. Mol Ecol Notes. 2004;4:137-8.

28. Earl DA, vonHoldt BM. STRUCTURE HARVESTER: a website and program for visualizing STRUCTURE output and implementing the Evanno method. Conserv Genet Resour. 2012;4:359-61.

29. Evanno G, Regnaut S, Goudet J. Detecting the number of clusters of individuals using the software structure: a simulation study. Mol Ecol. 2005:14:2611-20

30. Peakall R, Smouse PE. GENALEX 6: genetic analysis in Excel. Population genetic software for teaching and research. Mol Ecol Notes. 2006;6:288-95.

31. Peakall R, Smouse PE. GENALEX 6.5: genetic analysis in Excel. Population genetic software for teaching and research-an update. Bioinformatics. 2012;28:2537-9.

32. Langella O. Populations 1.2.28 (12/5/2002): A population genetic software. 2000. http://bioinformatics.org/ tryphon/populations/. Accessed on 20 Nov 2014

33. Saitou $N$, Nei M. The neighbor-joining method: a new method for reconstructing phylogenetic trees. Mol Biol Evol. 1987:4:406-25.

34. Piry S, Alapetite A, Cornuet JM, Paetkau D, Baudouin L, Estoup A. GENECLASS2: a software for genetic assignment and first-generation migrant detection. J Hered. 2004;95:536-9.

35. Rannala B, Mountain JL. Detecting immigration by using multilocus genotypes. Proc Natl Acad Sci U S A. 1997;94:9197-201.

36. Beaumont MA, Nichols RA. Evaluating loci for use in the genetic analysis of population structure. Proc R Soc B. 1996;263:1619-26.
37. McGinnity P, Prodöhl P, Ferguson A, Hynes R, Maoiléidigh NO, Baker N, et al. Fitness reduction and potential extinction of wild populations of Atlantic salmon, Salmo salar, as a result of interactions with escaped farm salmon. Proc R Soc B. 2003;270:2443-50.

38. Araki H, Berejikian BA, Ford MJ, Blouin MS. Fitness of hatchery-reared salmonids in the wild. Evol Appl. 2008;1:342-55.

39. ICES. Report of the Baltic salmon and trout assessment working group (WGBAST): 22-30 March 2011. 8th ed. Riga: ICES 2011/ACOM; 2011. p. 297.

40. Samuiloviene A, Kontautas A, Gross R. Genetic diversity and differentiation of sea trout (Salmo trutta) populations in Lithuanian rivers assessed by microsatellite DNA variation. Fish Physiol Biochem. 2009:35:649-59.

41. Leliűna E. Assessment of genetic structure of sea trout (Salmo trutta trutta L.) populations in the Nemunas river tributaries based on mitochondrial DNA variation. Acta Zool Lit. 2010;20:112-8.

42. Tonteri A, Veselov AJe, Titov S, Lumme J, Primmer CR. The effect of migratory behaviour on genetic diversity and population divergence: a comparison of anadromous and freshwater Atlantic salmon Salmo salar. J Fish Biol. 2007;70:381-98.

\section{Submit your next manuscript to BioMed Central and take full advantage of:}

- Convenient online submission

- Thorough peer review

- No space constraints or color figure charges

- Immediate publication on acceptance

- Inclusion in PubMed, CAS, Scopus and Google Scholar

- Research which is freely available for redistribution 